\title{
Reactions of a stable dialkylsilylene and their mechanisms
}

\author{
MITSUO KIRA ${ }^{\mathrm{a}, \mathrm{b}}$ \\ a'Department of Chemistry, Graduate School of Science, Tohoku University, Aoba-ku, Sendai 980-8578, Japan \\ ${ }^{b}$ Key Laboratory of Organosilicon Chemistry and Material Technology of Ministry of Education, Hangzhou \\ Normal University, Hangzhou 310012, China \\ e-mail: mkira@m.tohoku.ac.jp
}

\begin{abstract}
Various reactions for a stable dialkylsilylene, 2,2,5,5-tetrakis(trimethylsilyl)silacyclopentane-1,1diyl (1), are summarized and their mechanisms are discussed. Silylene $\mathbf{1}$ isomerizes to the corresponding silaethene via the 1,2-trimethylsilyl migration. Reduction of $\mathbf{1}$ with alkali metals affords the corresponding radical anion $\mathbf{1}^{--}$with a relatively small ${ }^{29} \mathrm{Si}$ hfs constant $(2.99 \mathrm{mT})$ and a large g-factor $(\mathrm{g}=2.0077)$ compared with those for trivalent silyl radicals. Photo-excitation of $\mathbf{1}$ generates the corresponding singlet excited state $\left(1^{1 *}\right)$ with the lifetime of $80.5 \mathrm{~ns}$. The excited state reacts with $\mathrm{C}=\mathrm{C}$ double bond compounds including benzene, naphthalene, and $(E)$ - and $(Z)$-2-butenes. Although the thermal reactions of $\mathbf{1}$ with haloalkanes occur via radical mechanisms, the insertion into $\mathrm{O}-\mathrm{H}, \mathrm{Si}-\mathrm{H}$ and $\mathrm{Si}-\mathrm{Cl}$ bonds proceeds concertedly via the threemembered cyclic transition states. The reaction of $\mathbf{1}$ with $\mathrm{H}_{2} \mathrm{SiCl}_{2}$ gives the $\mathrm{Si}-\mathrm{Cl}$ insertion product exclusively, while the quantitative insertion to $\mathrm{Si}-\mathrm{H}$ bond occurs when $\mathrm{Me}_{2} \mathrm{SiHCl}$ is used as a substrate. The origin of the rather unusual $\mathrm{Si}-\mathrm{H} / \mathrm{Si}-\mathrm{Cl}$ selectivity is elucidated using DFT calculations. Silylene $\mathbf{1}$ adds to $\mathrm{C}=\mathrm{C}, \mathrm{C} \equiv \mathrm{C}$, and $\mathrm{C}=\mathrm{O} \pi$ bonds to afford the corresponding silacycles as stable compounds. The importance of the carbonyl silaylides during the reactions of silylenes with aldehydes and ketones is emphasized.
\end{abstract}

Keywords. Stable silylene; mechanisms; photoreaction; addition; insertion; DFT.

\section{Introduction}

Silylenes, silicon divalent compounds, are important reactive intermediates in organosilicon chemistry just like carbenes in organic chemistry. A number of organic and inorganic silylenes have been studied as transient species since more than 40 years. As a typical organosilylene, dimethylsilylene is generated by various methods including thermolysis of 7,7-dimethylsilanorbornadiene at $350^{\circ} \mathrm{C},{ }^{1} 1,2$-dimethoxytetramethyldisilane at $225^{\circ} \mathrm{C},{ }^{2}$ and hexamethylsilirane at $>60^{\circ} \mathrm{C},{ }^{3}$ and photolysis of linear and cyclic permethylpolysilanes at lower temperatures, ${ }^{4}$ as shown in scheme 1 .

A number of other silylenes such as di-tert-butylsilylene, ${ }^{5}$ phenylmethylsilylene, ${ }^{6}$ diphenylsilylene, ${ }^{7}$ and bis[(2-dimethylaminomethyl)phenyl] silylene $^{8}$ are also available as transient silylenes using related generation methods as above. It is, therefore, natural that the reactions of the transient silylenes with various reagents have been investigated extensively. ${ }^{9}$ Transient silylenes dimerize to disilenes, insert into various single bonds such as $\mathrm{L}-\mathrm{H}(\mathrm{L}=\mathrm{O}, \mathrm{N}, \mathrm{S}, \mathrm{B}, \mathrm{Si}, \mathrm{Ge}$, halogens, etc.) and $\mathrm{Si}-\mathrm{X}(\mathrm{X}=\mathrm{Si}$, halogens $)$, add to unsaturated bonds $(\mathrm{C}=\mathrm{C}, \mathrm{C} \equiv \mathrm{C}, \mathrm{C}=\mathrm{O}, \mathrm{C}=\mathrm{N}$, etc. $)$ to form the corresponding silacycles and their derivatives, and complex to transition metals. Some of these reactions provide useful synthetic methods for the organosilicon compounds that are difficult to be synthesized by other methods, and are important as silylene trapping reactions to prove the generation and existence of transient silylenes in different systems. Although much attention has been focused on the mechanistic aspects of the unique silylene reactions, the studies have often been limited because of the transient nature of the silylenes.

We have synthesized an isolable dialkylsilylene $\mathbf{1}$ in $1999,{ }^{10}$ after the synthesis of stable decamethylsilicocene $2^{11}$ and cyclic diaminosilylenes $\mathbf{3},{ }^{12} \mathbf{4},{ }^{13} \mathbf{5 a},{ }^{14}$ and $\mathbf{5} \mathbf{b}^{15}$ (chart 1). Silicocene $\mathbf{2}$ is a rather exceptional silicon divalent compound with $\eta^{5}$-pentamethylpentadienyl ligands. Diaminosilylenes $\mathbf{3}-\mathbf{5 b}$ are stable divalent dicoordinate silylenes but stabilized electronically by the strong interaction between the vacant $\mathrm{p}_{\pi}$-orbital at the divalent atom and filled $\mathrm{p}_{\pi}$-type lone-pair orbitals of neighbouring heteroatoms. More recently, Driess et al. have succeeded to synthesize diaminosilylene $\mathbf{6}^{16}$ as a novel stable silylene. ${ }^{17,18}$ Dialkylsilylene $\mathbf{1}$ is less electronically perturbed than 3-6 and close to dialkyl- and diarylsilylenes in the electronic nature, while the steric bulkiness of $\mathbf{1}$ is much larger than the transient dialkyland diarylsilylenes.

Various unimolecular and bimolecular reactions of silylene $\mathbf{1}$ are discussed here, apart from the synthesis, structure, and spectroscopic properties of $\mathbf{1}$ that have been previously reviewed. ${ }^{10 \mathrm{~b}-\mathrm{e}}$ The reactions and 


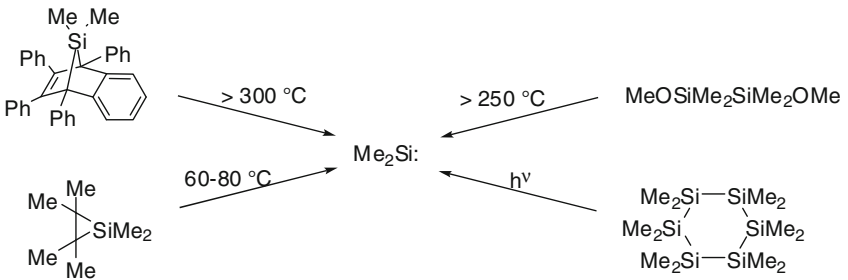

Scheme 1. Transient dimethylsilylene generated by different methods.

mechanisms of $\mathbf{1}$ will be compared directly with those of dialkyl- and diarylsilylenes accumulated over long periods of time. ${ }^{9}$

\section{Intramolecular 1,2-silyl migration}

Isolable dialkylsilylene $\mathbf{1}$ is storable at $0^{\circ} \mathrm{C}$ in the solid state but isomerizes slowly to the corresponding silaethene 6 via an apparent 1,2-silyl migration at room temperature in solution (eq. 1, hereafter, $s i=\mathrm{SiMe}_{3}$ unless otherwise noted). ${ }^{10 \mathrm{a}, 19}$ The firstorder rate constants for the isomerization in hexane have been determined UV-vis spectroscopically at various temperatures; the rate constant, activation enthalpy $\left(\Delta H^{\neq}\right)$and activation entropy $\left(\Delta S^{\neq}\right)$at $298 \mathrm{~K}$ are $6.24 \times 10^{6} \mathrm{~s}^{-1}, 18.49 \pm 0.43 \mathrm{kcal} \mathrm{mol}^{-1}$ and $-20.32 \pm$ $1.35 \mathrm{cal} \mathrm{mol}^{-1} \mathrm{~K}^{-1}$, respectively.

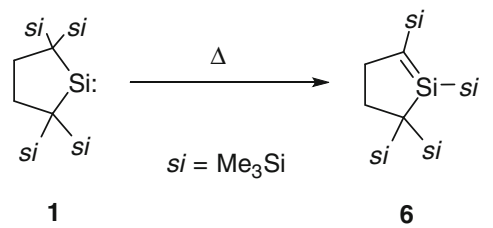

Relative stability between a silene and the corresponding silylene and the barrier separating the two species have intrigued both experimental and theoretical silicon chemists. Experimentally, very few studies have been proposed that silene-to-silylene isomerization occurs during the high-temperature thermolysis of silacyclobutanes and polysilanes. ${ }^{20}$ Theoretical studies have shown that the silylene-silene relative energy is small but the barrier is high, while they are strongly dependent on the substituents. ${ }^{9 f, 21}$ Typically, Nagase and $\mathrm{Kudo}^{21 \mathrm{~b}}$ have shown that the isomerization between 7a and 8a and that between $7 \mathbf{c}$ and $\mathbf{8 c}$ is almost thermoneutral, while ethylsilylene $\mathbf{7 b}$ is $10.3 \mathrm{kcal} \mathrm{mol}^{-1}$ less stable than methylsilene $\mathbf{8 b}$ at the MP3/6-31G* level (eq. 2). The barrier heights for the isomerization of $\mathbf{7 a}, \mathbf{7 b}$, and $\mathbf{7 c}$ into $\mathbf{8 a}, \mathbf{8 b}$, and $\mathbf{8 c}$ are calculated to be $43.0,44.4$, and $24.8 \mathrm{kcal} \mathrm{mol}^{-1}$, indicating that the barrier for 1,2-silyl migration $(\mathbf{7 c} \rightarrow \mathbf{8 c}$ ) is remarkably lower than those for 1,2-hydrogen and 1,2-methyl migration.

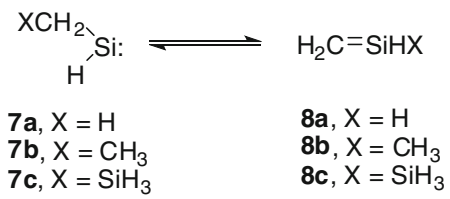

The relatively large negative $\Delta S^{\ddagger}$ value for the isomerization of $\mathbf{1}$ to $\mathbf{6}$ suggests that the transition state of this isomerization would have a significantly restricted structure, and therefore, any multi-step mechanism involving bond-cleavage at the rate controlling step may be eliminated from possible mechanisms. The $\Delta H^{\ddagger}$ value is consistent with the theoretical barrier for the isomerization from $\mathbf{7 c}$ to $\mathbf{8 c}$ calculated by Nagase and Kudo $\left(E_{\mathrm{a}}=24.8 \mathrm{kcal} \mathrm{mol}^{-1}\right.$ at MP3/6-31G* level $),{ }^{21 \mathrm{~b}}$ suggesting that the present isomerization is a concerted intramolecular 1,2-silyl migration via the cyclic transition state similar to that located theoretically for the isomerization of $\mathbf{1 c}$ to $\mathbf{2 c}$. Silene $\mathbf{6}$ is thermally very stable; no reaction occurred when $\mathbf{6}$ was heated in benzene at $90^{\circ} \mathrm{C}$ for 25 days. The irreversible thermal silyleneto-silene isomerization suggests that silylene $\mathbf{3}$ is more than $3 \mathrm{kcal} \mathrm{mol}^{-1}$ less stable than silene $\mathbf{4}$ in this particular case.

Germanium and tin analogues of silylene $\mathbf{1}$ are thermally stable, ${ }^{22}$ showing no isomerization into the corresponding germene and stannene occurs even at $100^{\circ} \mathrm{C}$. The results are in agreement with the general trend that group-14 divalent species become more stable relative to the corresponding doubly bonded compounds with

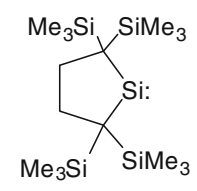

1

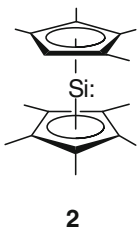

2

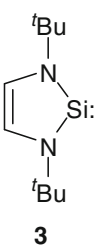

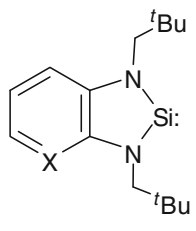

5a, $\mathrm{X}=\mathrm{CH}$ $5 b, X=N$

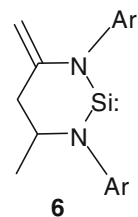

Chart 1. Isolable base-free silylenes. 
increasing the atomic number among the heavier group14 metal elements. A theoretical study on the isomerization of 1 to $\mathbf{6}$ (eq. 1 , si $=\mathrm{SiH}_{3}$ ) and its germanium and tin versions has shown that the activation energy and the relative stability of metallylene both increased in the order $\mathrm{E}=\mathrm{Si}<\mathrm{Ge}<\mathrm{Sn} .{ }^{19}$

\section{One-electron reduction forming radical ion}

Although a number of studies of the formation of silylene, germylene and stannylene radical anions have been reported, there are very few reports on the formation via the direct one electron reduction of the corresponding metallylenes; radical anions of stable germylene and stannylene have been produced by alkali metal reduction in solution and characterized by ESR spectroscopy. ${ }^{23}$ West et al. have reported that reduction of stable diaminosilylene $\mathbf{3}$ with potassium graphite in THF gave the corresponding 1,2-dipotassiodisilane which would be formed via fast dimerization of the silylene radical anion. ${ }^{24}$

One-electron reduction of dialkylsilylene $\mathbf{1}$ using alkali metals generates the corresponding radical anion as a relatively persistent species at low temperatures in solution (eq. 3). ${ }^{25}$ Using ESR spectroscopy, unique structural characteristics of the radical anion have been revealed. Related radical (anion) species have been investigated by Apeloig et al. ${ }^{26}$ and Sekiguchi et al. ${ }^{27}$

$$
\begin{aligned}
& 1 \underset{\text { DME, 213 K }}{\stackrel{\text { Alkali Metal }}{\longrightarrow}}[\underbrace{s i}_{s i}{ }_{s i}^{s i}]^{\mathrm{M}^{+}} \\
& 1^{\cdot-} \\
& M=L i, N a, K, \text { etc. }
\end{aligned}
$$

The ESR parameters of $\mathbf{1}^{-}$with $\mathrm{K}^{+}$as a countercation in DME are the following: $\mathrm{a}\left({ }^{29} \mathrm{Si}^{\alpha}\right) / \mathrm{mT}=2.99$, $\mathrm{a}\left({ }^{29} \mathrm{Si}^{\gamma}\right) / \mathrm{mT}=1.30$ and 1.66 , and $\mathrm{g}=2.0077$. The ESR parameters are independent of the countercations, indicating $\mathbf{1}^{-}$is free in DME. The $a\left({ }^{29} \mathrm{Si}^{\alpha}\right)$ value of $\mathbf{1}^{-}$is the smallest and its $\mathrm{g}$ factor is the largest among those of related trialkylsilyl and tris(trialkylsilyl)silyl radicals reported. According to the local symmetry of silylenes $\left(\mathrm{R}_{2} \mathrm{Si}\right.$ :, $\left.C_{2 v}\right)$, the singly occupied MO of $\mathbf{1}^{--}$ should be comprised of a pure $3 \mathrm{p}_{\pi}$ orbital perpendicular to the $\mathrm{R}_{2} \mathrm{Si}$ plane. Since the $\mathrm{a}\left({ }^{29} \mathrm{Si}^{\alpha}\right)$ value involves no direct contribution from the s character of the SOMO, the hfs would originate mostly from the spin polarization of the $\mathrm{C}-\mathrm{Si}^{\alpha} \sigma$ bonds. The large $\mathrm{g}$ factor is ascribed to the contribution of the small excitation energy of $\mathrm{n} \rightarrow \operatorname{SOMO}\left(3 \mathrm{p}_{\pi}\right)$ in $\mathbf{1}^{-}$. Formation of the persistent anion radical by the reduction of silylene $\mathbf{1}$ and its ESR spectrum is a good indication of the existence of the low-lying $\mathrm{p}_{\pi}$ LUMO of silylene $\mathbf{1}$.

\section{Photo-excited state and its addition reactions to $\mathrm{C}=\mathrm{C}$ bonds}

Because silylenes are usually in the singlet ground state and absorb Uv-vis lights, the silylenes can form the singlet excited states by photo-irradiation. However, little is known about the properties of the excited states, whereas several unimolecular reactions of the excited states of matrix-isolated silylenes at low-temperatures have been investigated. ${ }^{28}$

Irradiation of silylene 1 with filtered light $(\lambda>$ $420 \mathrm{~nm}$ ) at room temperature in benzene affords the corresponding silacycloheptatriene in the quantitative yield (eq. 4), whereas only the isomerization of $\mathbf{1}$ into $\mathbf{6}$ is observed in the dark. ${ }^{29 a}$

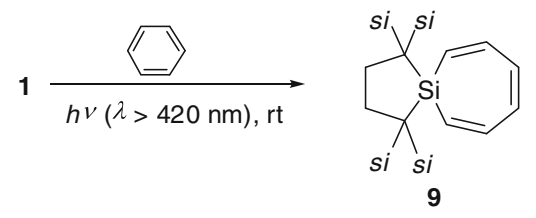

Singlet nature of the excited state responsible for the photoreaction of $\mathbf{1}$ is evidenced by fluorescence quenching in the presence of benzene. ${ }^{29 b}$ The fluorescence maximum $\lambda^{\mathrm{fl}}{ }_{\text {max }}$ of $\mathbf{1}$ in hexane is observed at $610 \mathrm{~nm}$ with the life time $\left(\tau_{0}\right)$ of $80.5 \mathrm{~ns}$; the $\lambda^{\mathrm{fl}}{ }_{\text {max }}$ value is close to that reported for dimethylsilylene in a 3-methylpentane matrix $\left(\lambda^{\mathrm{fl}}{ }_{\max }=650 \mathrm{~nm}\right) \cdot{ }^{30}$ Using the dependence of the life time on the concentration of benzene, the quenching rate constant $k_{\mathrm{q}}$ was determined to be $9.4 \times 10^{6} \mathrm{M}^{-1} \mathrm{~s}^{-1}$. The above photoreaction is suggested to occur through the collision between the singlet excited state of $\mathbf{1}^{1 *}$ and benzene. Why the reacting excited state is not the lowest triplet state $\left({ }^{3} \mathrm{~B}_{1}\right)$ but the lowest singlet state $\left({ }^{1} \mathrm{~B}_{1}, \mathbf{1}^{1 *}\right)$ is rationalized by the El-Sayed rule. ${ }^{31}$ Although the ${ }^{3} \mathrm{~B}_{1}$ state is lower lying than the ${ }^{1} \mathrm{~B}_{1}$ state, intersystem crossing from ${ }^{1} \mathrm{~B}_{1}$ to ${ }^{3} B_{1}$ requires either a $3 p$ or an $n$ electron spin inversion, and hence, the process is forbidden according to the El-Sayed rule; large ${ }^{3} \mathrm{~B}_{1}-{ }^{1} \mathrm{~B}^{1}$ energy difference of ca. $30 \mathrm{kcal} \mathrm{mol}^{-1}$ will also contribute to the lifetime extension. Relatively long lifetime of $\mathbf{1}^{1 *}$ allows the reaction of the excited state with benzene.

The detailed mechanism for the reaction of $\mathbf{1}^{1 *}$ with benzene may be delineated by the analogy of wellknown aromatic silyl radical substitution. ${ }^{29 a}$ Because $\mathbf{1}^{1 *}$ is a singlet 1,1-biradical in nature, the addition to benzene gives the 1,3-biradical intermediate. Successive cyclization to the corresponding silanorcaradiene 
followed by the $\mathrm{C}-\mathrm{C}$ bond cleavage leads to the final silacycloheptatriene $\mathbf{9}$ (eq. 5).

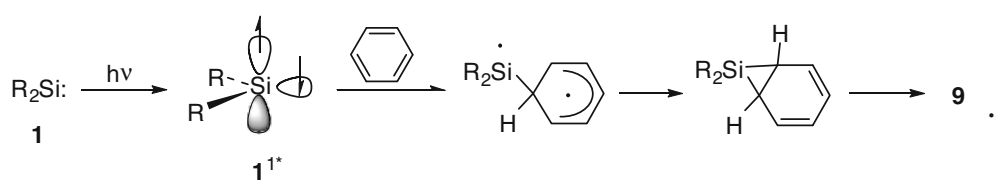

Although a transient silylene has been reported to react with benzene thermally by Tokitoh, Okazaki, et al. ${ }^{32}$ silylene $\mathbf{1}$ at the ground state does not react with benzene. The reason is ascribed to the steric hindrance between silylene $\mathbf{1}$ and benzene. Because benzene serves usually as a nucleophile, it should favour to approach the LUMO of $\mathbf{1}$. However, the $\mathrm{p} \pi$ LUMO is sterically well protected by the helmet-like bidentate ligand. In contrast, the less hindered in-plane radical site of $\mathbf{1}^{1 *}$ may approach the benzene to accomplish aromatic radical addition, as shown in eq. 5 .

The photochemical addition of $\mathbf{1}$ to various aromatic and aliphatic $\mathrm{C}=\mathrm{C}$ bonds occurs smoothly if the double bond is not sterically hindered (eqs 6-8). Silylene 1 reacts with $(E)$-2-butene stereospecifically under irradiation to afford the corresponding silirane $\mathbf{1 3}$ in the quantitative yield, while the thermal reaction of $\mathbf{1}$ with the butene give a complex mixture; thermal addition reactions of $\mathbf{1}$ to alkenes are discussed more in detail in the later section.

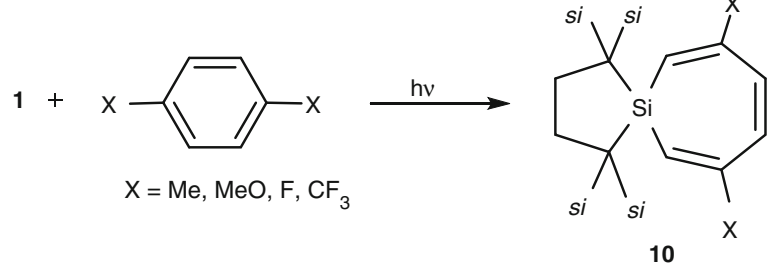

(6)

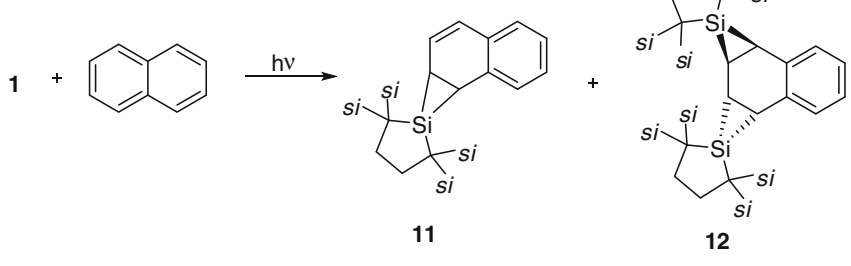

(7)

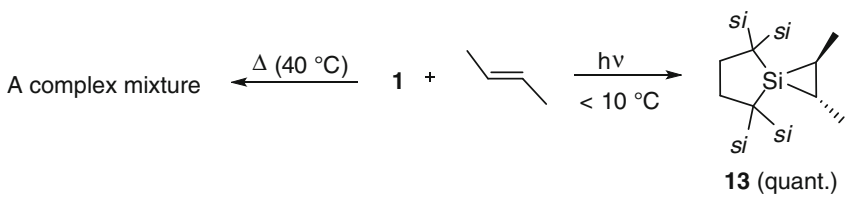

(8)

\section{Insertion into $\sigma$ bonds}

Insertion into $\sigma$ bonds is one of the fundamental and useful reactions of heavy group-14 divalent species including silylenes. ${ }^{9}$ The insertion of silylenes into various $\sigma$ bonds such as $\mathrm{O}-\mathrm{H}, \mathrm{N}-\mathrm{H}, \mathrm{C}-\mathrm{X}$ (C-halogen, strained $\mathrm{C}-\mathrm{O}$, intramolecular $\mathrm{C}-\mathrm{H}$, etc.) and $\mathrm{Si}-\mathrm{X}$ $(\mathrm{X}=\mathrm{H}, \mathrm{O}, \mathrm{N}$, halogen, and $\mathrm{Si})$ bonds has been extensively studied so far both experimentally and theoretically. Isolable dialkylsilylene $\mathbf{1}$ insert probably concertedly into various $\sigma$ bonds such as $\mathrm{O}-\mathrm{H}$ and $\mathrm{Si}-\mathrm{H}$ bonds in high yields (eq. 9). ${ }^{10 \mathrm{a}}$

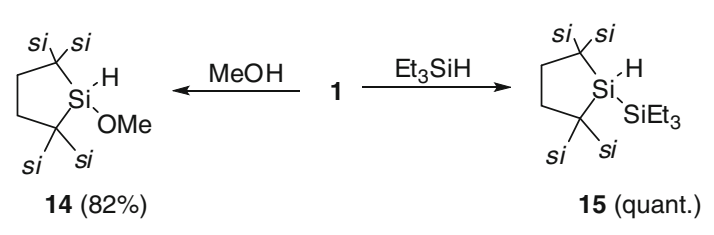

Insertion of $\mathbf{1}$ into C-halogen bonds is not straightforward. Although the insertion of $\mathbf{1}$ into the C-halogen bonds of $\mathrm{MeI}$ and $n$ - $\mathrm{BuCl}$ gives simple insertion products $16 \mathbf{a}$ and $\mathbf{1 6 b}$ but that into cyclopropylmethyl chloride affords a rather unusual 1:2 adduct $\mathbf{1 7}$ in $70 \%$ yield together with dichlorosilane $\mathbf{1 8}$ in $15 \%$ yield (eq. 10). ${ }^{33}$ The reaction profile suggests that the reactions of $\mathbf{1}$ with various alkyl halides proceed through a radical mechanism rather than the ionic or concerted mechanisms. ${ }^{33,34}$

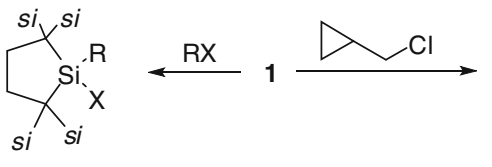

16a, $R=M e, X=I(88 \%)$ 16b, $\mathrm{R}=n-\mathrm{Bu}, \mathrm{X}=\mathrm{Cl}(77 \%)$

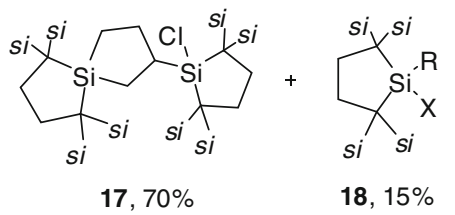


Dialkylsilylene 1 has been found to insert smoothly into a $\mathrm{Si}-\mathrm{Cl}$ bond of tetrachlorosilane and other chlorosilanes (scheme 2). ${ }^{35}$ In contrast to the insertion into Chalogen bonds, the $\mathrm{Si}-\mathrm{Cl}$ insertion would undergo the concerted process.

However, interesting differences are found in the reactivity between $\mathrm{Si}-\mathrm{H}$ and $\mathrm{Si}-\mathrm{Cl}$ insertion reactions. ${ }^{35 \mathrm{~b}}$ Silylene 1 inserts into the $\mathrm{Si}-\mathrm{H}$ bond of triethylsilane, while 1 does not react with trimethylchlorosilane. The reaction of 1 with $\mathrm{H}_{2} \mathrm{SiCl}_{2}$ gives the $\mathrm{Si}-\mathrm{Cl}$ insertion product 23 exclusively, while the insertion to $\mathrm{Si}-\mathrm{H}$ bond occurs to give $\mathbf{2 2}$ when $\mathrm{Me}_{2} \mathrm{SiHCl}$ is used as a substrate (eq. 11).

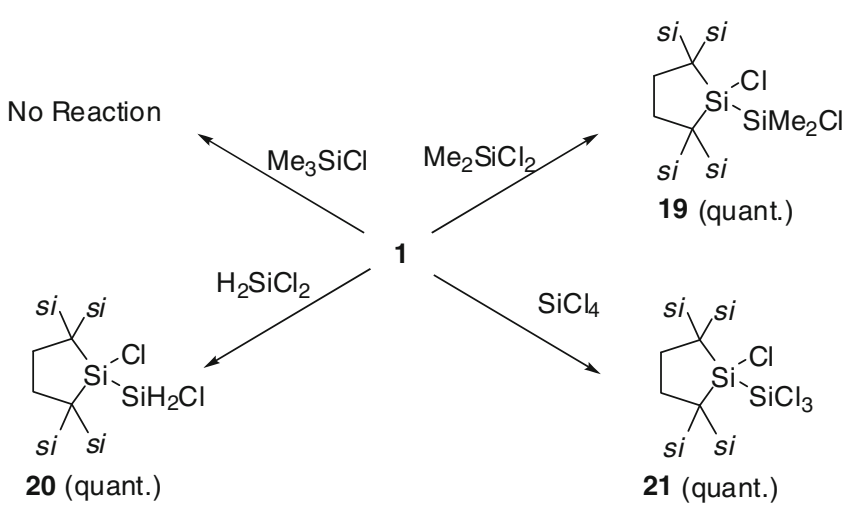

Scheme 2. Reactions of $\mathbf{1}$ with various chlorosilanes.

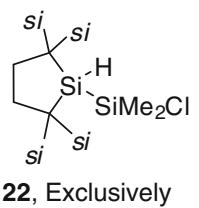

$\frac{\mathrm{Me}_{2} \mathrm{SiHCl}}{\text { Si-H insertion }}$

22, Exclusively
$1 \stackrel{\mathrm{H}_{2} \mathrm{SiCl}_{2}}{\mathrm{Si}-\mathrm{Cl} \text { insertion }} \underset{S i}{\mathrm{Si}_{\mathrm{Si}}^{-} \mathrm{Sl}_{\mathrm{SiH}} \mathrm{Cl}}$

23, Exclusively
To understand rather unexpected selectivity of the insertion ( $\mathrm{Si}-\mathrm{H} / \mathrm{Si}-\mathrm{Cl}$ selectivity), insertion reactions of dimethylsilylene and silylene $\mathbf{1}$ ' into a $\mathrm{Si}-\mathrm{H}$ and a $\mathrm{Si}-$ $\mathrm{Cl}$ bond of various substituted hydro- and chlorosilanes have been studied computationally using DFT with the $6-31++\mathrm{G}(\mathrm{d}, \mathrm{p})$ basis set (eqs 12 and 13). ${ }^{36,37}$

$$
\begin{aligned}
& \mathrm{R}_{2} \mathrm{Si}:+\mathrm{YR}_{2}{ }_{2} \mathrm{Si}-\mathrm{Cl} \longrightarrow \mathrm{YH}_{2} \mathrm{Si}_{-} \mathrm{SiMe}_{2}-\mathrm{Cl} \\
& 2425 \\
& \begin{array}{cc}
\mathrm{R}_{2} \mathrm{Si}: & +\mathrm{YR}_{2}{ }_{2} \mathrm{Si}-\mathrm{H} \\
\mathbf{2 6} & \underset{27}{\mathrm{YH}_{2} \mathrm{Si}_{-}-\mathrm{SiMe}_{2}-\mathrm{H}} \\
& \longrightarrow
\end{array}
\end{aligned}
$$

All the insertion reactions investigated are largely exothermic and proceed via the three-membered cyclic transition states with one substituent (Y) of a hydro- and chlorosilane in the ring plane and two other substituents ( $\mathrm{R}^{\prime}$ ) out of the plane, as shown schematically in figure $1 .{ }^{36}$

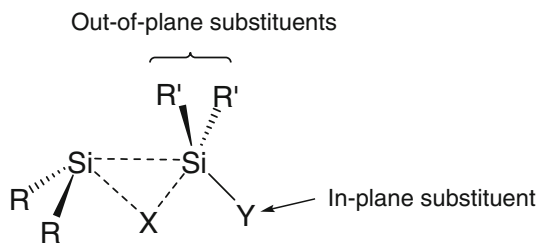

Figure 1. Schematic representation of the transition states for the insertion of a silylene into $\mathrm{Si}-\mathrm{X}$ bonds $(\mathrm{X}=\mathrm{H}, \mathrm{Cl})$.
Our theoretical calculations indicate that while the activation energy for the prototype insertion of a dialkylsilylene into a $\mathrm{Si}-\mathrm{H}$ bond of $\mathrm{SiH}_{4}$ is only $1.5 \mathrm{kcal}$ $\mathrm{mol}^{-1}$ lower than that for the insertion into a $\mathrm{Si}-\mathrm{Cl}$ bond of $\mathrm{SiH}_{3} \mathrm{Cl}$, the energy is strongly affected by the substituents on silane and silylene silicon atoms. Substituent effects on the activation free energy of the insertion of a dialkylsilylene into a $\mathrm{Si}-\mathrm{X}$ bond $(\mathrm{X}=\mathrm{H}, \mathrm{Cl})$ are separated into three roughly independent factors; (i) electronic in-plane and (ii) steric out-of-plane substituent effects of $\mathrm{Si}-\mathrm{X}$ compounds and (iii) steric bulkiness of the dialkylsilylene. Difference in the $\mathrm{Si}-\mathrm{H} / \mathrm{Si}-$ $\mathrm{Cl}$ selectivity observed between the reactions of silylene 1 with $\mathrm{H}_{2} \mathrm{SiCl}_{2}$ and $\mathrm{Me}_{2} \mathrm{SiHCl}$ is explained by strong directing effects of chlorine substituent, which lowers the $\Delta \mathrm{G}^{\neq}$value as an in-plane substituent but increases it as an out-of-plane substituent. ${ }^{36 \mathrm{c}}$

The insertion reaction of $\mathbf{1}$ to a $\mathrm{Si}-\mathrm{Cl}$ bond is applied to the synthesis of various stable compounds with silicon-silicon unsaturated bonds such as a trisilaallene and related trimetallaallenes, ${ }^{35 a, 38 a}$ tetrasila-1,3diene, ${ }^{39}$ and aryldisilenes ${ }^{40}$ (eqs $14-16$ ).

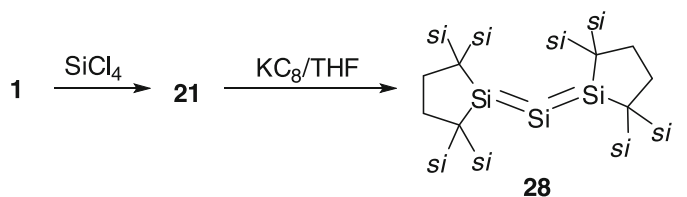




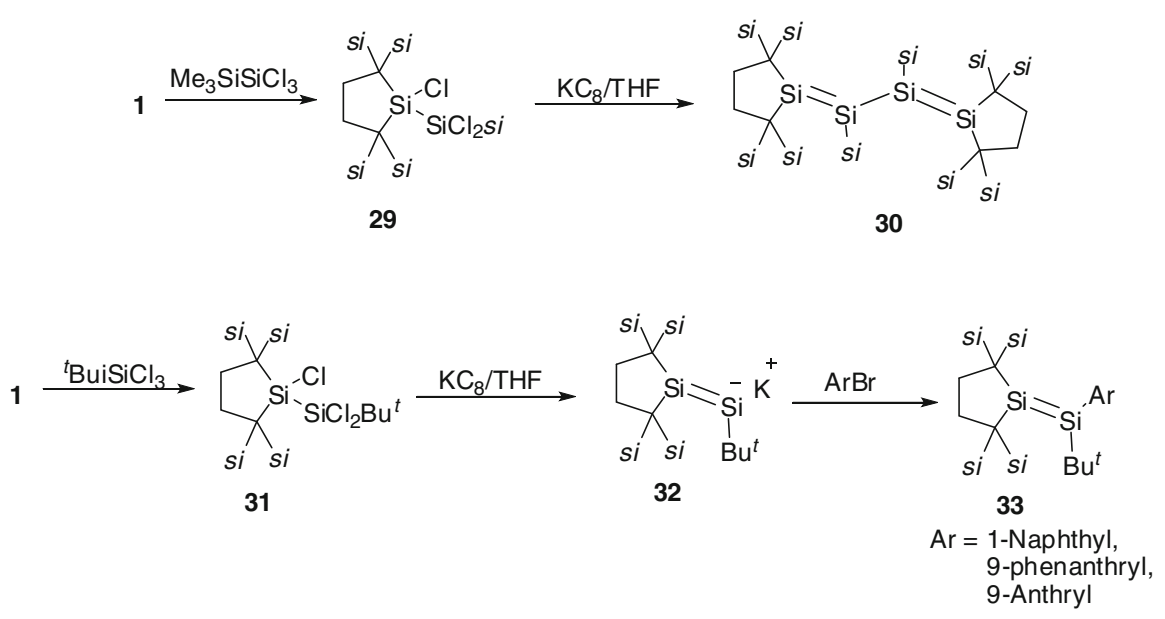

\section{Addition to $\pi$ bonds}

The reactions of silylene 1 with ethylene, $(Z)$-2-butene, acetylene, bis(trimethylsilyl)acetylene, and 2,3-dimethylbutadiene at room temperature gave the corresponding silacycles in high yields (scheme 3). ${ }^{41}$ Usually, the $C$ unsubstituted silacyclopropanes and silacyclopropenes are highly reactive in the air but compounds $\mathbf{3 4}$ and 36 are isolated as air-stable compounds because of the effective steric protection at silicon. ${ }^{42}$ The reaction of 1 with $(E)$-2-butene gives a complex mixture indicating no formation of the corresponding silirane, in contrast to the photochemical reaction of $\mathbf{1}$ with the alkene (vide supra). These reactions are supposed to occur concertedly similar to the addition of singlet carbenes to unsaturated bonds. The reactivity difference between $(Z)$ - and (E)-2-butenes to $\mathbf{1}$ is compatible with the relative addition rate of silylenes to $(Z)-/(E)$-2-butenes; the rates for the stereospecific $[1+2]$ cycloaddition of dimesitylsilylene to $(Z)$-2-butene have been reported to be $25-28$ times faster than that to $(E)$-2-butene. ${ }^{43}$

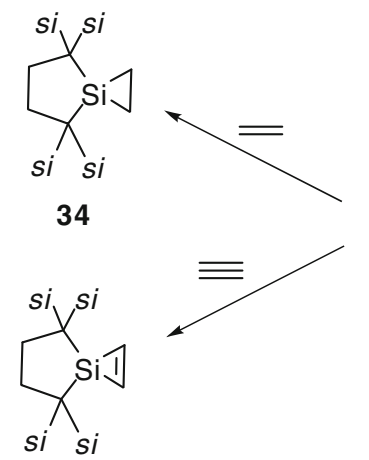

36
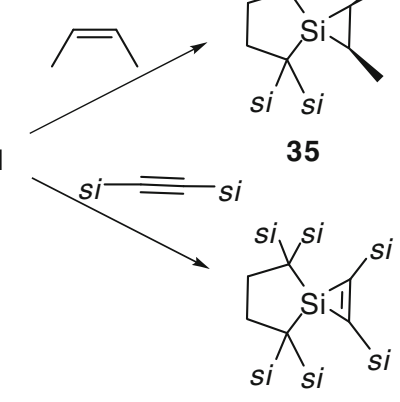

37

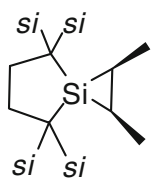

35
Scheme 3. Reactions of silylene $\mathbf{1}$ with alkenes and alkynes.
Although the reactions of silylenes with 1,3-butadienes are well-known to afford the corresponding vinylsiliranes and silacyclopent-3-enes, the selectivity and its origin have not been well understood even now. ${ }^{9 \mathrm{~d}, 44}$ The reaction of $\mathbf{1}$ with 2,3-dimethylbutadiene affords the corresponding [ $1+4]$ cycloadduct $\mathbf{3 8}$ in $90 \%$ yield without contamination of the $[1+2]$ cycloadduct 39 (scheme 4). ${ }^{10 a, 41}$ Theoretical mechanistic studies on the selective 1,2-/1,4-addition reactions of dialkylsilylenes with butadienes are in progress.

The reactions of transient silylenes with aldehydes and ketones have been investigated extensively as one of the fundamental reactions of silylenes. ${ }^{9}$ The reactions gave diverse types of final products including $1: 1$ and 1:2 adducts depending on the structures of silylenes and carbonyl compounds. We have investigated the reactions of isolable dialkylsilylene $\mathbf{1}$ with different types of ketones. ${ }^{45}$ All the reactions proceeded smoothly at room temperatures to afford single 1:1 adducts in high yields without formation of any secondary or side-reaction products.

The reaction of $\mathbf{1}$ with adamantanone gives the corresponding silaoxirane $\mathbf{4 0}$, while that with acetone, an enolizable ketone, gives the corresponding silyl enol ether 41 (eq. 17).

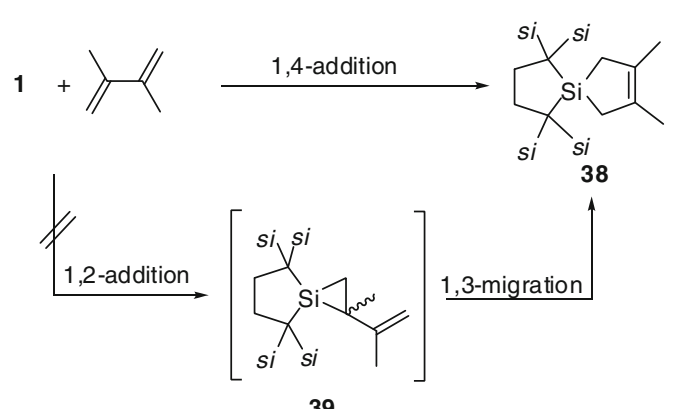

Scheme 4. Two possible pathways of the reaction of $\mathbf{1}$ with 2,3-dimethylbutadiene giving a 1,4-adduct. 


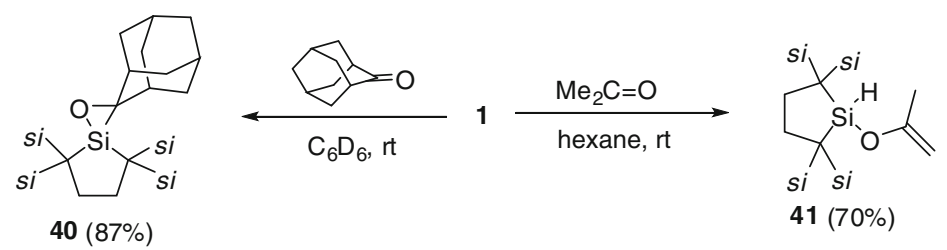

Benzophenone reacts with $\mathbf{1}$ to afford 2- gradually aromatize to $\mathbf{4 3}$ at room temperature oxasilacyclopentene $\mathbf{4 2}$ as yellow crystals, which (eq. 18).

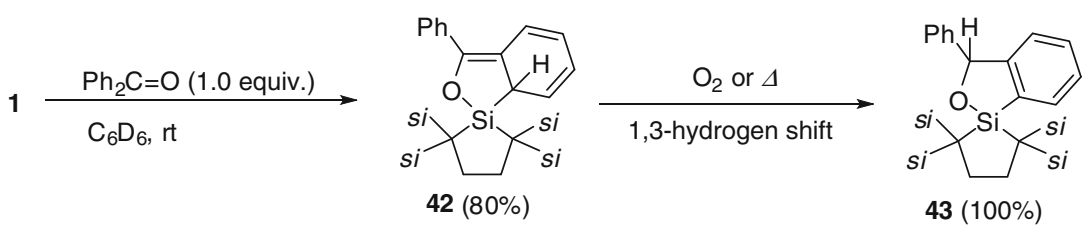

Rather unusual products $\mathbf{4 4 a}$ and $\mathbf{4 4 b}$ are obtained during the reactions of $\mathbf{1}$ with di-tert-butyl- and diphenylcyclopropenones, respectively, as single diastereomers (eq. 19).

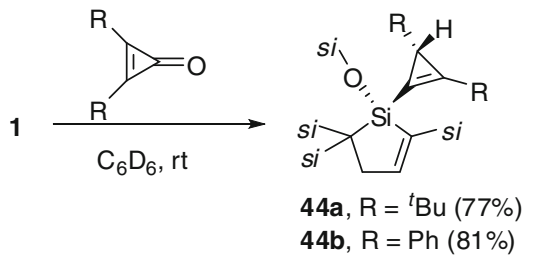

The diverse reaction modes of silylene $\mathbf{1}$ and other transient silylenes with carbonyl compounds may be explained by taking into account the initial formation of the corresponding carbonyl silaylides, as widely accepted. The carbonyl silaylides cyclize to the corresponding silaoxiranes and react with another carbonyl molecule to afford the 1:2 adduct. However, the electronic nature of carbonyl silaylides as 1,3-dipoles should be dependent on the substituents on both silicon and carbonyl carbon atoms, as shown by the two representative resonance forms in eq. 20.
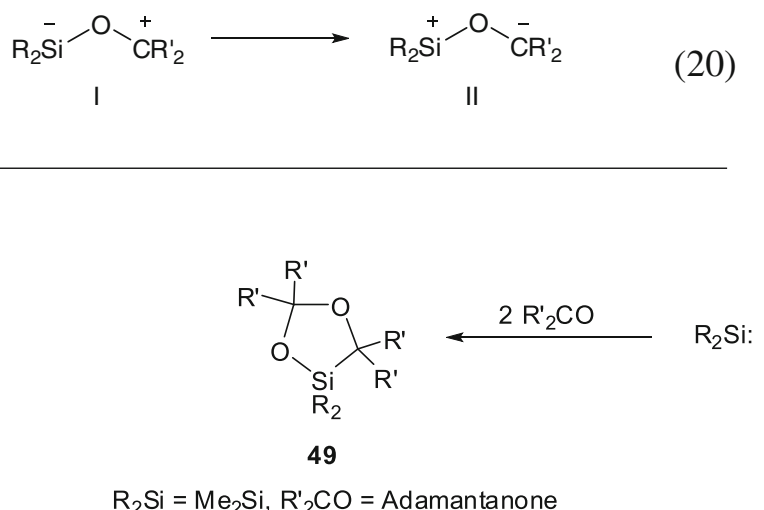

$\mathrm{R}_{2} \mathrm{Si}=\mathrm{Me}_{2} \mathrm{Si}, \mathrm{R}_{2} \mathrm{CO}=$ Adamantanone
Actually, theoretical calculations at the B3LYP/6$31+\mathrm{G}(\mathrm{d})$ level for $\mathrm{Me}_{2} \mathrm{Si}-\mathrm{O}-\mathrm{CR}_{2}$-type silaylides have shown that the charge distribution and geometry of the 1,3-dipoles at the optimized structure are remarkably modified by the substituents on carbon or the nature of the carbonyl compounds. ${ }^{45}$ The Mulliken charge on $\mathrm{Me}_{2} \mathrm{Si}$ moiety is negative for carbonyl silaylide 45 but increases in the order $45<46<$ $47<48$, while the group charge of $\mathrm{R}_{2}{ }_{2} \mathrm{C}$ decreases in the same order (chart 2). Sum of bond angles at the $\mathrm{Si}$ atom $(\Sigma @ \mathrm{Si})$ increases in the same order, indicating the pyramidal character at the $\mathrm{Si}$ atom decreases in the order $45>46>47>48$. Evidently, with increasing electron accepting ability of substituents on carbonyl carbon of the carbonyl silaylides, both the positive charge on $\mathrm{SiR}_{2}$ and $\Sigma @ \mathrm{Si}$ increase.

The reaction of dimethylsilylene with adamantanone gives 1:2 adduct 49 among other products, ${ }^{46}$ while the reaction of bis(2-dimethylaminomethylphenyl)silylene with fluorenone ${ }^{47}$ and that of decamethylsilicocene with benzaldehyde ${ }^{48}$ give the corresponding 1:2 adducts 50 with different regioselectivity (eq. 21), which will be ascribed to the difference in nature among intermediate silaylides.

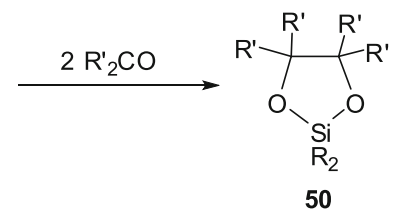

$\mathrm{R}_{2} \mathrm{Si}=2-\mathrm{Me}_{2} \mathrm{NCH}_{2} \mathrm{C}_{6} \mathrm{H}_{4}, \mathrm{R}_{2} \mathrm{CO}=$ fluorenone $\mathrm{R} 2 \mathrm{Si}=$ decamethylsilycocene, $\mathrm{R}_{2} \mathrm{CO}=$ benzaldehyde 


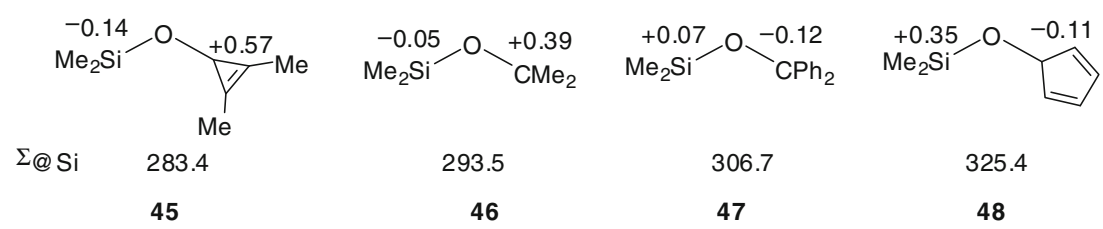

Chart 2. Substituent dependence of Mulliken charge distributions of carbonyl silaylides. The left and right numbers on a molecule show the group charge of $\mathrm{Me}_{2} \mathrm{Si}$ and alkyl moieties, respectively.

The products of the reactions of silylene $\mathbf{1}$ with cyclopropenones (eq. 19) will be obtained through the rearrangement of the corresponding carbonyl silaylide intermediates as shown in eq. 22.

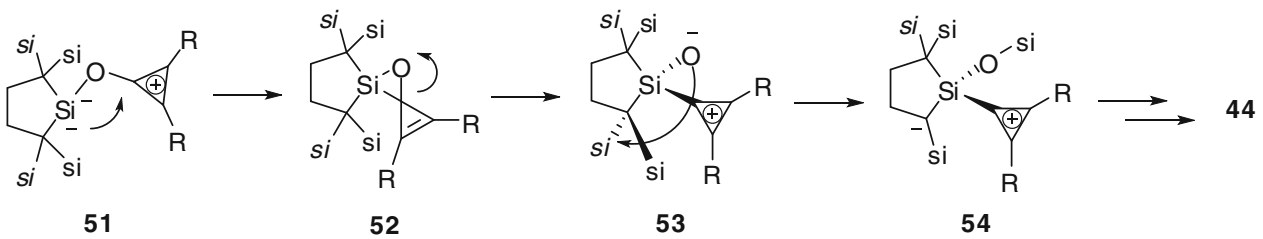

\section{Miscellany}

Heavy metallanechalcogenones are known to be derived by the reactions of the corresponding metallylenes with chalcogens and their equivalents. ${ }^{49}$ Silylene 1 reacts with phosphine sulphide and elemental selene and telurium to give the corresponding silicon-chalcogen double bond compounds $\mathbf{5 1 - 5 3}$ (eq. 23). ${ }^{50}$ When $\mathbf{1}$ is treated with elemental sulphur $S_{8}$, tetrathiasilolane $\mathbf{5 4}$ is obtained as the major product, which is transformed to silanethione $\mathbf{5 1}$ quantitatively by treating with triphenylphosphine (eq. 24).

$$
\begin{aligned}
& 1 \underset{\text { hexane }}{\stackrel{\text { Reagent }}{\longrightarrow}} \stackrel{\text { si }}{X_{\text {si }}^{s i}=\mathrm{x}} \\
& \text { 51, } \mathrm{X}=\mathrm{S} \text { (Reagent }=\mathrm{Me}_{3} \mathrm{P}=\mathrm{S} \text { ), } 72 \% \\
& \text { 52, } X=S e \text { (Reagent }=\text { Element Se), } 92 \% \\
& \text { 53, } X=\text { Te (Reagent = Element Te), } 99
\end{aligned}
$$

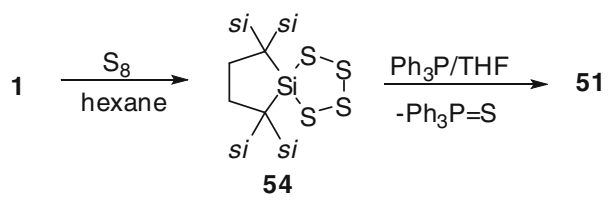

Silylene 1 reacts with isocyanides with a bulky substituent at the nitrogen atom to afford isolable silaketeneimines 55 and 56 in high yields (eq. 25). Silaketeneimines $\mathbf{5 5}$ and $\mathbf{5 6}$ are stable in the solid state below $0^{\circ} \mathrm{C}$ but dissociate to silylene $\mathbf{1}$ and the corresponding isocyanides in solution even at $-30^{\circ} \mathrm{C}$.

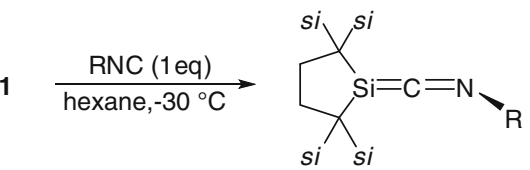

$$
\begin{aligned}
& \text { 55, } R=2,6 \text {-diisopropylphenyl, } 89 \% \\
& 56, R=1 \text {-Adamantyl, } 85 \%
\end{aligned}
$$

Tokitoh, Okazaki et al. have first synthesized silaketenimines with bulky aryl-substituents at silicon and have concluded that they are characterized as silylene-isocyanide complexes rather than silaketenimines on the basis of spectroscopic data, theoretical calculations, and their reactions. ${ }^{51}$ The X-ray structural analysis has shown that $\mathbf{5 5}$ and $\mathbf{5 6}$ are characterized to be allenic rather than zwitterionic or silyleneisocyanide complex. The bonding characteristics of silaketenimines are concluded to be affected strongly by the substituents on silicon and nitrogen atoms. ${ }^{52}$

Since the pioneering works by Zybill et al. ${ }^{53 a}$ and Tilley et al. ${ }^{53 \mathrm{~b}}$ various base-stabilized and base-free silylene complexes have been synthesized and their versatile reactivity has been explored. ${ }^{54}$ Products of the reaction of 1 with $\left(\mathrm{Cy}_{3} \mathrm{P}\right)_{2} \mathrm{Pd}$ depend strongly on the ratio of the two substrates. The reaction of the $1: 1$ molar ratio of silylene 1 to $\left(\mathrm{Cy}_{3} \mathrm{P}\right)_{2} \mathrm{Pd}$ gives the corresponding monosilylenepalladium complex 57 in a high yield as an air-sensitive purple oil, whereas the isolation was unsuccessful due to the contamination of free 
tricyclohexylphosphine. ${ }^{55}$ a When the 2:1 ratio of $\mathbf{1}$ to $\left(\mathrm{Cy}_{3} \mathrm{P}\right)_{2} \mathrm{Pd}$ is used, the corresponding bis(silylene)Pd $\mathbf{5 8}$ is obtained in a high yield (eq. 26). ${ }^{55 \mathrm{a}, \mathrm{b}}$ The reaction of the 1:2 mixture of $\mathbf{1}$ to $\left(\mathrm{Cy}_{3} \mathrm{P}\right)_{2} \mathrm{Pd}$ affords a dinuclear palladium complex with a bridging dialkylsilylene ligand 59. ${ }^{55 \mathrm{~b}}$

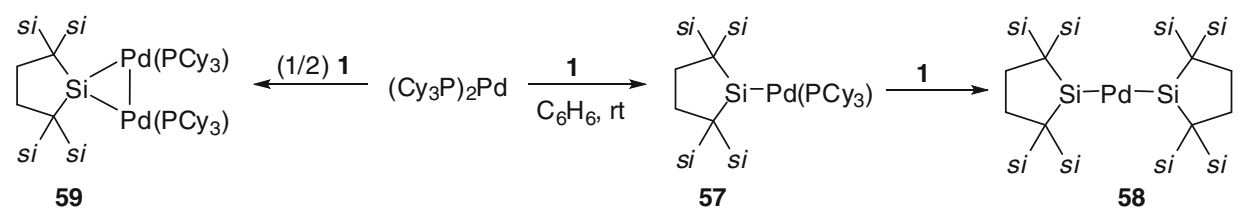

The reaction of silylene $\mathbf{1}$ with bis(1,5cyclooctadiene)nickel $\left[\mathrm{Ni}(\operatorname{cod})_{2}\right]$ in toluene gives (monosilylene)nickel complex $\mathbf{6 0}$ almost quantitatively (eq. 27). ${ }^{55 \mathrm{c}} \mathrm{A}$ similar (monosilylene)nickel complex is obtained by the reaction of diaminosilylene $\mathbf{6}$ with $\mathrm{Ni}(\mathrm{cod})_{2},{ }^{56}$ while diaminosilylenes $\mathbf{3}$ and $\mathbf{5 a}$ have been reported to react with $\mathrm{Ni}(\operatorname{cod})_{2}$ to afford nickel complexes with three and four silylene ligands. ${ }^{57}$

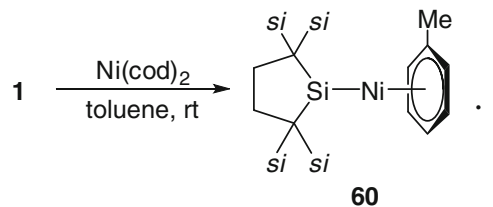

\section{Conclusion}

Studies of the reactions of isolable dialkylsilylene $\mathbf{1}$ have revealed that the reaction modes are not limited to $\sigma$ bond insertion and $\pi$ bond addition that are usually found for transient organic silylenes such as dimethylsilylene and diphenylsilylene, but are more diversified including the bimolecular photoreactions, one-electron reduction, and intramolecular isomerization. Silylene 1 and other stable silylenes are useful as precursors for the synthesis of stable silicon unsaturated compounds and other unique silicon compounds. As a distinctive electronic system, the stable silylenes may fulfil a central function in optoelectronic devices.

\section{Acknowledgements}

The author is grateful to his former colleagues and students, especially Prof. T Iwamoto, Dr. S Ishida, and Dr. C Kabuto, Tohoku University, Japan, and present colleagues at Hangzhou Normal University, China, Profs. G Lai, J Jiang, and Z Li, and $\mathrm{Dr}$. Z Xu, for their active collaboration. This work was supported financially by the Ministry of Education, Culture, Sports, Science and Technology of Japan (Grants-in-Aid for Scientific Research (C) No. 22550028).

\section{References}

1. Gilman H, Cottis S G and Atwell W H $1964 \mathrm{~J}$. Am. Chem. Soc. 861596

2. Atwell W H and Weyenberg D R 1966 J. Organomet. Chem. 5594

3. (a) Seyferth D and Annarelli D C $1975 \mathrm{~J}$. Am. Chem. Soc. 97 2273; (b) Seyferth D and Annarelli D C 1975 J. Am. Chem. Soc. 97 7162; (c) Seyferth D, Annarelli D C and Vick S C 1976 J. Am. Chem. Soc. 98 6382; (d) Seyferth D, Annarelli D C and Duncan D P 1982 Organometallics 11288

4. (a) Ishikawa M and Kumada M $1970 \mathrm{~J}$. Chem. Soc. D Chem. Commun. 6129; (b) Sakurai H, Kobayashi Y and Nakadaira Y 1971 J. Am. Chem. Soc. 935272

5. (a) Weidenbruch M, Schäfer A and Thom K L 1983 Z. Naturforsch. Teil B 38 1695; (b) Boudjouk P, Samaraweera U, Sooriyakumaran R, Chrusciel J and Anderson K R 1988 Angew. Chem. Int. Ed. Engl. 27 1355; (c) Boudjouk P, Black E and Kumarathasan R 1991 Organometallics 10 2095; (d) Calad S A and Woerpel K A 2005 J. Am. Chem. Soc. 1272046

6. (a) Ishikawa M and Kumada M 1974 J. Organomet. Chem. 81 C3; (b) Ishikawa M, Ohi F and Kumada M 1975 J. Organomet. Chem. 86 C23

7. (a) Konieczny S, Jacobs S J, Braddock-Wilking J K and Gaspar P P 1988 J. Organomet. Chem. 341 C17; (b) Moiseev A G and Leigh W J $2006 \mathrm{~J}$. Am. Chem. Soc. 12814442

8. (a) Belzner J and Ihmels H 1993 Tetrahedron Lett. 34 6541; (b) Belzner J, Ihmels H, Kneisel B O, Gould R O and Herbst-Irmer R 1995 Organometallics 14305

9. For reviews of transient silylenes see: (a) Atwell W H and Weyenberg D R 1969 Angew. Chem. Int. Ed. Engl. 8 469; (b) Gaspar P P 1978 in Reactive intermediates, vol. 1, M Jones and R A Moss (eds) (New York: Wiley); (c) Gaspar P P 1981 in Reactive intermediates, vol. 2, M Jones and R A Moss (eds) (New York: Wiley); (d) Gaspar P P 1985 in Reactive intermediates, vol. 3, M Jones and R A Moss (eds) (New York: Wiley); (e) Ishikawa M and Kumada M 1981 Adv. Organomet. Chem. 19 51; (f) Gaspar P P and West R 1998 in The chemistry of organic silicon compounds, vol. 2, part 3, Z Rappoport and Y Apeloig (eds) (New York: Wiley); (g) Atwell W H 2009 Organometallics 283573

10. (a) Kira M, Ishida S, Iwamoto $\mathrm{T}$ and Kabuto C 1999 J. Am. Chem. Soc. 121 9722; (b) Kira M 2004 J. Organomet. Chem. 689 4475; (c) Kira M, Ishida S and Iwamoto T 2004 Chem. Rec. 4 243; (d) Kira M, Iwamoto 
T and Ishida S 2007 Bull. Chem. Soc. Jpn. 80 258; (e) Kira M 2010 Chem. Commun. 462893

11. (a) Jutzi P, Kanne D and Krüger C 1986 Angew. Chem. Int. Ed. Engl. 25 164; (b) Jutzi P, Holtmannm U, Kanne D, Krueger C, Blom R, Gleiter R and Hyla-Krypsin I 1989 Chem. Ber. 122 1629; (c) Jutzi P, Becker A, Stammler H G and Neumann B 1991 Organometallics 101647

12. (a) Denk M, Lennon R, Hayashi R, West R, Belyakov A V, Verne H P, Haaland A, Wagner M and Metzler N 1994 J. Am. Chem. Soc. 116 2691; (b) West R and Denk M 1996 Pure Appl. Chem. 68785

13. (a) Denk M, Green J C, Metzler N and Wagner M 1994 J. Chem. Soc. Dalton Trans. 2405; (b) Schmedake T A, Haaf M, Apeloig Y, Müller T, Bukalov S and West R 1999 J. Am. Chem. Soc. 1219479

14. (a) Gehrhus B, Lappert M F, Heinicke J, Boese R and Bläser D 1995 J. Chem. Soc. Chem. Commun. 1931; (b) Gehrhus B, Hitchcock P B, Lappert M F, Heinicke J, Boese R and Bläser D 1996 J. Organomet. Chem. 521 211

15. Heinicke J, Opera A, Kindermann M K, Karbati T, Nyulászi L and Veszprémi T 1998 Chem. Eur. J. 4541

16. Driess M, Yao S, Brym M, van Wüllen C and Lentz D 2006 J. Am. Chem. Soc. 1289628

17. Recently stable base-coordinate halosilylenes have been developed by Roesky et al.: (a) So C W, Roesky H W, Magull J and Oswald R B 2006 Angew. Chem. Int. Ed. 45 3948; (b) Ghadwal R S, Roesky H W, Merkel S, Henn J and Stalke D 2009 Angew. Chem. Int. Ed. 48 5683

18. For reviews of stable silylenes see: (a) Driess $M$ and Grutzmacher H 1996 Angew. Chem. Int. Ed. Engl. 36 828; (b) Barrau J and Ghassoub R 1998 Coord. Chem. Rev. 178 593; (c) Jutzi P and Burford N 1999 Chem. Rev. 99 969; (d) Tokitoh N and Okazaki R 2000 Coord. Chem. Rev. 210 251; (e) Weidenbruch M 2002 J. Organomet. Chem. 646 39; (f) Weidenbruch M 2003 Organometallics 22 4348; (g) Hill N J and West R 2004 J. Organomet. Chem. 689 4165; (h) Mizuhata Y, Sasamori T and Tokitoh N 2009 Chem. Rev. 1093479

19. Ishida S, Iwamoto T and Kira M 2009 Organometallics 28919

20. (a) Conlin R T and Wood D L 1981 J. Am. Chem. Soc. 103 1843; (b) Barton T J, Burns S A and Burns G T 1982 Organometallics 1210 ; (c) Barton T J, Burns G T, Goure W F and Wulff W D 1982 J. Am. Chem. Soc. 104 1149; (d) Burns S A, Burns G T and Barton T J 1982 J. Am. Chem. Soc. 104 6140; (e) Barton T J, Burns S A and Burns G T 1983 Organometallics 2 199; (f) Davidson I M T, Ijadi-Maghsoodi S, Barton T J and Tillman N 1984 J. Chem. Soc. Chem. Commun. 478; (g) Ando W, Hamada Y, Sekiguchi A 1982 J. Chem. Soc. Chem. Commun. 787; (h) Sekiguchi A and Ando W 1983 Tetrahedron Lett. 242791

21. (a) Schaefer H F III 1982 Acc. Chem. Res. 15 283; (b) Nagase S and Kudo T 1984 J. Chem. Soc. Chem. Commun. 1392; (c) Grev R S, Scuseria G E, Scheiner A C Schaefer H F III and Gordon M S 1988 J. Am. Chem. Soc. 110 7337; (d) Apeloig Y 1989 in The chemistry of organic silicon compounds, vol. 1, S Patai and Z Rappoport (eds) (Chichester: Wiley); (e) Boatz J A and Gordon M S 1990 J. Phys. Chem. 947331
22. (a) Kira M, Yauchibara R, Hirano R, Kabuto C and Sakurai H 1991 J. Am. Chem. Soc. 113 7785; (b) Kira M, Ishida S, Iwamoto T, Ichinohe M, Kabuto C, Ignatovich L and Sakurai H 1999 Chem. Lett. 28 263; (c) Kira M, Ishida S, Iwamoto T, Yauchibara R and Sakurai H 2001 J. Organomet. Chem. 636144

23. Egorov M P, Nefedov O M, Lin T-S and Gaspar P P 1995 Organometallics $\mathbf{1 4} 1539$

24. Schmedake T A, Haaf M, Paradise B J and West R 2000 Can. J. Chem. 781526

25. Ishida S, Iwamoto T and Kira M 2003 J. Am. Chem. Soc. 1253212

26. A related radical, $\left[\mathrm{Li}\left({ }^{i} \operatorname{Pr}_{3} \mathrm{Si}\right)_{2}\right] \mathrm{Si}$, was generated and investigated by ESR spectroscopy: BravoZhivotovskii D, Yuzefovich M, Sigal N, Korogodsky G, Klinkhammer K, Tumanskii B, Shames A and Apeloig Y 2002 Angew. Chem. Int. Ed. 41649

27. Stable silylene radical anions were isolated by Sekiguchi et al. but not by a direct one-electron reduction of the corresponding silylene: Inoue $\mathrm{S}$, Ichinohe $\mathrm{M}$ and Sekiguchi A 2007 J. Am. Chem. Soc. 1296096

28. (a) Drahnak J, Michl J and West R 1979 J. Am. Chem. Soc. 101 5427; (b) Arrington C A, Klingensmith K A, West R and Michl J 1984 J. Am. Chem. Soc. 106 525; (c) Dhananjay D J and Fink M J 1989 J. Am. Chem. Soc. 111 5921; (c) Welsh K, Michl J and West R 1988 J. Am. Chem. Soc. 110 6689; (d) Maier G, Pacl H, Reisenauer H P, Meudt A and Janoschek R 1995 J. Am. Chem. Soc. 11712712

29. (a) Kira M, Ishida S, Iwamoto $\mathrm{T}$ and Kabuto C 2002 J. Am. Chem. Soc. 124 3830; (b) Kira M, Ishida S, Iwamoto T, de Meijere A, Ito O and Fujitsuka M 2004 Angew. Chem. Int. Ed. $\mathbf{4 3} 4512$

30. Drahnak T J, Michl J and West R 1979 J. Am. Chem. Soc. 1015427

31. (a) El-Sayed M A 1962 J. Chem. Phys. 36 573; (b) ElSayed M A 1963 J. Chem. Phys. 38 2834; (c) El-Sayed M A 1964 J. Chem. Phys. 41 2462; (d) El-Sayed M A 1968 Acc. Chem. Res. 1 8; (e) Lower S K and El-Sayed M A 1966 Chem. Rev. 66199

32. Suzuki H, Tokitoh N and Okazaki R 1994 J. Am. Chem. Soc. 11611572

33. Ishida S, Iwamoto T, Kabuto C and Kira M 2001 Chem. Lett. 331102

34. For mechanisms proposed for the reactions of diaminosilylenes with haloalkanes see: (a) Moser D F, Bosse T, Olson J, Moser J L, Guzei I A and West R 2002 J. Am. Chem. Soc. 124 4186; (b) Su M-D 2003 J. Am. Chem. Soc. 125 1714; (c) Xiong Y, Yao S and Driess M 2009 Organometallics 281927

35. (a) Ishida S, Iwamoto T, Kabuto C and Kira M 2003 Nature 421 725; (b) Ishida S, Iwamoto T, Kabuto C and Kira M 2003 Silicon Chem. 2137

36. (a) Lai G, Xu Z, Li Z, Jiang J, Kira M and Qiu H 2009 Organometallics 28 3591; (b) Xu Z, Jin J, Li Z, Qiu H, Jiang J, Lai G and Kira M 2009 Chem. Eur. J. 15 8605; (c) Xu Z, Jin J, Zhang H, Li Z, Jiang J, Lai G and Kira M 2011 Organometallics 303311

37. For a recent discussion on the $\mathrm{Si}-\mathrm{H}$ bond insertion of metallylenes see: Karni M, Kapp J, Schleyer P v R and Apeloig Y 2001 in The chemistry of organic silicon compounds, vol. 3, Z Rappoport and Y Apeloig (eds) (Chichester: Wiley) and references therein 
38. (a) Iwamoto $\mathrm{T}$, Masuda H, Kabuto $\mathrm{C}$ and Kira M 2005 Organometallics 24 197; (b) Iwamoto T, Abe T, Kabuto C and Kira M 2005 Chem. Commun. 41 5190; (c) Kira M, Iwamoto T, Ishida S, Masuda $\mathrm{H}$, Abe $\mathrm{T}$ and Kabuto C 2009 J. Am. Chem. Soc. 13117135

39. Uchiyama K, Nagendran S, Ishida S, Iwamoto $T$ and Kira M 2007 J. Am. Chem. Soc. 12910638

40. Iwamoto T, Kobayashi M, Uchiyama K, Sasaki S, Nagendran S, Isobe H and Kira M 2009 J. Am. Chem. Soc. 1313156

41. Ishida S, Iwamoto T and Kira M 2011 Heteroat. Chem. 22432

42. Before our reports C-unsubstituted silirane and silirene have been synthesized by Boudjouk et al. and Driess et al. respectively: (a) Boudjouk $\mathrm{P}$, Black E, Kumarathasan R 1991 Organometallics 10 2095; (b) Yao S, van Wüllen C, Sun X-Y and Driess M 2008 Angew Chem Int Ed. 473250

43. Zhang S, Wagenseller P-E and Conlin R T 1991 J. Am. Chem. Soc. 1134278

44. For a recent theoretical study of 12-/14-cycloaddition selectivity see: Nag M and Gaspar P P 2009 Organometallics 285612

45. Ishida S, Iwamoto T and Kira M 2010 Organometallics 295526

46. Ando W, Ikeno M and Sekiguchi A 1978 J. Am. Chem. Soc. 1003613

47. Belzner J, Ihmels H, Pauletto L and Noltemeyer M 1996 J. Org. Chem. 613315

48. Jutzi P, Eikenberg D, Bunte E A, Mohrke A, Neumann B and Stammler H G 1996 Organometallics 151930

49. For reviews see: (a) Tokitoh $\mathrm{N}$ and Okazaki R 1998 in The chemistry of organosilicon compounds, vol. 2, Z Rappoport and Y Apeloig (eds) (New York: Wiley); (b)
Okazaki R and Tokitoh N 2000 Acc. Chem. Res. 37 625; (c) Tokitoh N and Okazaki R 2001 Adv. Organomet. Chem. 47121

50. Iwamoto T, Sato K, Ishida S, Kabuto C and Kira M 2006 J. Am. Chem. Soc. 12816914

51. (a) Takeda N, Suzuki H, Tokitoh N, Okazaki R and Nagase S 1997 J. Am. Chem. Soc. 119 1456; (b) Takeda N, Kajiwara T, Suzuki H, Okazaki R and Tokitoh N 2003 Chem.-Eur. J. 93530

52. Abe T, Iwamoto T, Kabuto C and Kira M 2006 J. Am. Chem. Soc. 1284228

53. (a) Zybill C and Müller G 1987 Angew. Chem. Int. Ed. Engl. 26 669; (b) Strauss D A, Tilley T D, Reingold A L and Geib S J 1987 J. Am. Chem. Soc. 1095872

54. For recent reviews on silylene transition metal complexes see: (a) Tilley T D 1989 in The chemistry of organic silicon compounds, vol. 1, S Patai and Z Rappoport (eds) (New York: Wiley); (b) Eisen M S 1998 in The chemistry of organic silicon compounds, vol. 2, Z Rappoport and Y Apeloig (eds) (New York: Wiley); (c) Ogino H 2002 Chem. Rec. 2 291; (d) Okazaki M, Tobita H and Ogino H 2003 Dalton Trans. 493; (e) Waterman R, Hayes P G and Tilley T D 2007 Acc. Chem. Res. 40 712

55. (a) Watanabe C, Iwamoto T, Kabuto C, Kira M 2008 Angew. Chem. Int. Ed. 47 5386; (b) Watanabe C, Iwamoto T, Kabuto C and Kira M 2007 Chem. Lett. 36 284; (c) Watanabe C, Inagawa Y, Iwamoto T and Kira M 2010 Dalton Trans. 9414

56. Meltzer A, Präsang C, Milsmann C and Driess M 2009 Angew. Chem. Int. Ed. $\mathbf{4 8} 3170$

57. (a) Schmedake T A, Haaf M, Paradise B J, Powell D and West R 2000 Organometallics 19 3263; (b) Avent A G, Gehrhus B, Hitchcock P B, Lappert M F and Maciejewski H 2003 J. Organomet. Chem. 686321 